\title{
Liman Operasyonlarının Çevresel Etkileri
}

\author{
Muhammet BORAN ${ }^{1 *}$, Nigar ALKAN ${ }^{2}$ \\ ${ }^{1}$ Karadeniz Teknik Üniversitesi, Sürmene Deniz Bilimleri Fakültesi, Deniz Ulaştırma İşletme Mühendisliğe Bölümü, \\ Trabzon, Türkiye \\ ${ }^{2}$ Karadeniz Teknik Üniversitesi, Sürmene Deniz Bilimleri Fakültesi, Balıkçılık Teknolojisi Mühendisliği Bölümü, \\ Trabzon, Türkiye
}

"Sorumlu Yazar: mboran@ktu.edu.tr

Geliş Tarihi: 09.07.2018

Kabul Tarihi: 05.09 .2018

\section{$\ddot{O} \mathbf{z}$}

$\mathrm{Bu}$ çalışmada, liman faaliyetlerinden kaynaklanan çevresel problemeler ortaya konulmuştur. Limanalar bulundukları bölgelerde hava, su ve toprak kirliliğine neden olmaktadır. Limanların konumları, sınıfı, operasyon yoğunluğu, elleçelenen yük çeşitleri ve yüklerin özellikleri, bunların çevresel etkileri üzerinde önemli role sahiptir. Limanlarda hava kirliliği; gemiler, tren, diğer yük taşıma araçları, kargo elleçleme ekipmanları, petrol ve gaz depolama tesisleri, açık kömür yığınları gibi ulaşım ve sabit kaynaklardan ileri gelmektedir. Diğer taraftan liman operasyonlarının deniz ortamında su kalitesi üzerinde önemli olumsuz etkileri vardır. Gemi kaynaklı evsel nitelikli atık sular, sintine suları, limanda yüzey akışına geçen yağmur suları, gemi boyası ve petrol sızıntısı ile diğer liman faaliyetlerinden kaynaklanan kirleticiler su kirliliğine neden olurlar. Limanlarda yapılan dip taramaları, habitatın hasar görmesine, siltasyon hızının değişimine ve liman içi suların oksijensiz hale gelmesine neden olur. Ayrıca gemi motorları, fanlar, vinçler, traktörler ve kamyonlar gibi birçok kaynak liman bölgelerinde gürültü kirliliğine neden olmaktadır.

Anahtar Kelimeler: Liman operasyonları, su kirliliği, deniz kirliliği, hava kirliliği.

\section{Environmental Impacts of Port Operations}

\begin{abstract}
This study discusses a number of different environmental problems related to port activities. The ports cause air, water and soil pollution in the surrounding area. Important factors such as port location, contraction and operations play an important role on the environmental impacts of ports. Some of the environmental problems caused by port activities are related to specific types of ships or cargo. Impact from loading and unloading and moving goods in the port area differs somewhat between the various types of cargo. Air pollution in ports is occurred by transportation and stationary sources such as tracks, vessels, train, cargo handling equipment, oil and gas storage facilities, power generation and storage of open piles of coal. In the other hand port operations can have a significant impact on water quality in the marine environment. Sewage and bilge water from ships, storm water runoff, ship paint, oil spill and other port activities can result water pollution and also harm marine life. Dredging for removing sediment from harbor bottom causes habitat damage, siltation rate change and deoxygenating. One of the other problems caused by port operations is noise pollution. Noise in port areas is caused by many sources, for example by ship engines, fans, cranes, tractors and trucks.
\end{abstract}

Key words: Port operations, water pollution, marine pollution, air pollution. 


\section{Giriş}

Deniz taşımacılık sisteminin en önemli unsurlarından biri olan limanlar, gemilerin yükleme boşaltma yaptıkları, barındıkları, yakıt kumanya ve diğer ihtiyaçlarını karşıladıkları yerlerdir. Limanlar bulundukları bölgelerin ekonomisine önemli katkılar yapmaktadırlar. Ancak ulusal ve uluslararası yük taşımacılığının önemli bir unsuru olan limanalar, özellikle çevre kirliliğini önlemeye yönelik altyapılarını iyi oluşturmadıkları ve bu konuyla ilgili iyi yönetilmedikleri takdirde bulundukları bölgede önemli çevre sorunlarının oluşmasına neden olurlar.

Limanların projelendirilmelerinde yer seçimi yapılırken; dalga iklimi ve akıntı yönleri, sediment hareketi, taşınım doğrultusu, akarsular, hidrografik ve topoğrafik koşullar, yeterli kara ve deniz alanının varlığı, jeolojik durum, kara ulaşım ağı yanında korunan tür ve alanlar da göz önünde bulundurulmaktadır. Kıyı alanlarına yapılan limanlar bu alanların plaj vb. gibi kullanımlarını engelleyeceğinden, insanların kıyı bölgeleri ile iletişiminin kesilmesine neden olurlar. Ayrıca limanlar haliç, bataklık, kum tepeleri vb. gibi kıyı alanlarında yer alan ekoton bölgelerin ortadan kalkmasına neden olurlar. Arazi değişikliklerinden dolayı ekonomik kayıpların oluşması, kıyı coğrafyasındaki değişikliklere bağlı olarak kıyısal ekosistemin bozulması özellikle emisyon sonucu çevreye yayılan gaz ve tozun limanların bulundukları bölgede yaşayan insanları etkilemesi, liman sahasında gece yapılan çalışmalarda gürültünün ortaya çıkması limanların canlı ve cansız çevre üzerine yaptığ 1 olumsuz etkilerdendir (ÇŞB, 2017).

Limanlar büyüklük ve trafik türüne göre değişiklik gösterirler. Bazıları endüstri limanları olup sadece birkaç petrol endüstrisi ve rafineri gibi özellikli alanlarda hizmet verirler. Limanların önemli bir kısmı ise bulundukları ülkelerde kamuya ait olup birçok gemi türünü kabul ederler. Bazı limanlar ise konteyner, ro-ro ve dökme yükler gibi belirli yük türleri için uzmanlaşmıştır (OECD, 2011).

Limanlar gelişim süreçlerinde, su kalitesini, kıyı hidrolojisini, deniz dibi tabanını, deniz ve kıyı ekolojisini, hava kalitesini bozarak bulundukları bölgede çevresel problemlere neden olurlar. Ayrıca gürültü kirliliğine neden olarak tüm canlıların yaşamını olumsuz olarak etkilerler. Limanların çevresel etkileri bu nedenle üç alt kategoriye ayrılabilir: Bunlardan birincisi liman faaliyetinin kendisinden kaynaklanan problemler; ikincisi denizde gemilerden kaynaklanan problemler ve üçüncüsü limana hizmet eden intermodal taşımacılık ağlarından kaynaklanan problemlerdir (Carlton ve College, 2010; OECD, 2011).

$\mathrm{Bu}$ çalışmanın amacı liman faaliyetlerinden kaynaklanan çevre kirliliğini ortaya koymaktır. 


\section{Materyal ve Metot}

Bu makale derleme çalışması olup çeşitli kaynaklardan alıntılar yapılarak yazılmıştır.

\section{Bulgular ve Tartışma}

\subsection{Egzoz Emisyonu}

Liman operasyonlarının çevresel etkilerinden en önemlisi gemi ve limanda yer alan diğer araç ve ekipmanlar ile limana giriş çıkış yapan araçlardan kaynaklanan egzoz emisyonunun oluşturduğu hava kirliliğidir. Özellikle ağır yakıtlar kullanmaları nedeniyle gemiler önemli derecede hava kirliliğine neden olmaktadırlar. Gemi kaynaklı hava kirliliğinde en büyük hava kirletici kaynaklar gemilerin ana makineleri ve jeneratörleridir. Gemilerden yakıt kullanımı sonucu atmosfere bulaşan başlıca hava kirleticiler, azot oksitler (NOx), kükürt oksitler $\left(\mathrm{SO}_{2}\right)$, karbondioksit $\left(\mathrm{CO}_{2}\right)$, hidrokarbonlar ( $\left.\mathrm{HC}\right)$ ve partikül maddelerdir (PM) (Deniz ve ark., 2010). Uçar (2014) tarafından Samsun ilinde gemi kaynaklı egzoz gazı emisyon yüklerine yönelik yapılan bir çalışmada, NOx 429.54 ton, karbondioksit 20246.3 ton, kükürtdioksit 338.31 ton, hidrokarbon 19.34 ton ve partikül madde miktarı ise 38.77 ton olarak belirlenmiştir. Çalışma sonunda Samsun ili hava kirliliğine gemi kaynaklı egzoz emisyonunun önemli düzeyde katkı yaptığı belirlenmiştir. Çandarlı körfezinde yapılan bir çalışmada, yıllık gemi kaynaklı emisyon yükünün 631.2 ton $\mathrm{NO}_{x}, 573.6$ ton $\mathrm{SO}_{2}, 33848.9$ ton $\mathrm{CO}_{2}, 32.3$ ton $\mathrm{HC}$ ve $57.4 \mathrm{PM}$ olduğu saptanmıştır. Aynı araştırmada Aliağa ve Nemrut körfezlerinde belirlenen emisyon düzeylerinin dünyadaki diğer benzer limanlardakinden daha yüksek olduğu vurgulanmıştır (Deniz ve ark., 2010).

\subsection{Gürülttü Kirliliği}

Yük elleçleme ekipmanları ve araç trafiği limanlardaki önemli gürültü ve titreşim kaynağıdır. Ayrıca gemiler yanaşma ve kalkma manevraları esnasında önemli düzeyde gürültüye neden olurlar. Yine limana yanaşmış gemilerde çalışan gemi yardımcı makineleri ile havalandırma sistemleri gürültü kaynağı olarak değerlendirilirler. Gemiler limanda manevra yaparken ana makinalarından yayılan gürültü oldukça yüksektir. Manevraya yardımcı olan diğer ekipmanların oluşturduğu gürültü de buna eklenince gürültü düzeyi daha da artmaktadır (Badino, 2012). Gürültü kirliliği hem doğal ekosistemi ve hem de liman çevresinde yaşayan insanları olumsuz etkilemektedir. Gürültü kirliliğinin insanlarda işitme, kardiyovasküler rahatsızlıklar, yüksek tansiyon, uyku bozuklukları, verimlilikte azalma ve zihinsel stres gibi hastalıklara neden olduğu Schenone ve ark., (2014) tarafindan bildirilmiştir. 


\subsection{Gemi Kaynaklı Kirleticiler}

Limanlarda su kirliliğine neden olabilecek muhtemel deşarjlar sintine ve balast suları ve evsel nitelikli atık sulardan oluşmaktadır. Ayrıca ambar yıkama suları ile güvertenin yıkanması sonucu oluşan yağlı ve deterjanlı suların denize verilmesi, gemi bordasında raspa ve boya işlemlerinin yapılması, yağmur sularının güvertedeki kirletici atıkları denize taşıması yakıt alımı esnasında yakıtın kaza sonucu denize sızması, gemi makinası soğutma suyuna yağ karışması ve bunun soğutma suyu ile denize boşalması, şaft sızdırmazlık yağı ile güverte donanımlarında bulunan hidrolik sistemlerden sızan yağın denize bulaşması, liman ve çevresindeki suların kirlenmesine neden olmaktadır (OECD, 2011; Andersson ve ark., 2016).

Gemilerin ürettiği çeşitli atıklar, denize boşaltımının engellenmesi ve buna bağlı olarak deniz çevresinin korunması amacıyla liman atık alım tesislerinde depolanmak ve işleme tabi tutulmak üzere limanlar tarafindan alınırlar. Bu atıklar; sintine, slaç, atık yağ, kirli balast, slop, zehirli sıvı maddeler, pissu atıkları, katı atıklar, yük istif ve bağlama malzemeleri ile gemilerin taşıdıkları katı yük atıklarından oluşur (Köseoğlu ve ark., 2016). Ancak ülkemizde birçok liman alım atık tesisi istenilen düzeyde işlevsel değildir. Özellikle petrol ve petrol türevi içeren kirli suların yeterince arıtılmadan deniz ortamına deşarj edilmesi veya şehir kanalizasyon şebekesine bırakılması liman ve çevresindeki denizel ortamın kirlenmesine neden olmaktadır. Ülkemizde limanların birçoğu atık kabul tesisi için lisans almış olmalarına rağmen, zaman içerisinde bu tesisler gemilerden alınan atıkların, geçici depolanması veya alıcı ortamlara verilecek düzeyde arıtılması için yetersiz kalmaktadırlar. Doğu Karadeniz limanlarındaki liman atık alım tesislerinin incelendiği bir çalışmada, bazı limanlarda sintine sularının dinlendirme yöntemiyle ayrıştırıldığı, bazı limanların sıvı atık depolama tank kapasitelerinin yetersiz olduğu belirlenmiştir (Gençtürk, 2012). Gemilerde personel ve yolcuların rutin operasyonları sonucu ile diğer işlemlerden kaynaklanan katı atıkların limanlarda uluslararası kurallara uymaksızın gelişi güzel denize atılması deniz suyunda fiziksel, kimyasal ve biyolojik kirliliğe neden olmaktadır (OECD, 2011).

\subsection{Tehlikeli Yükler}

Gemiler ile taşınan tehlikeli yükler bulundukları çevre için önemli sorunlar oluşturmaktadır. Bu yüklerin birçok türü limanlarda elleçlenmekte gemiler tarafından taşınmaktadır. Kostik soda, sülfürik asit, nitrik asit, fosforik asit, amonyak, kömür ve katran ürünleri bu grup ürünlere örnek olarak verilebilirler. Bu maddelerin limanlar veya terminallerde elleçlenmesi esnasında kaza sonucu çevreye bulaşması limanların çevresinde önemli çevresel problemlerin oluşmasına neden olurlar (OECD, 
2011). Denize bulaşan bu maddeler deniz ekosistemini olumsuz etkileyebilecekleri gibi insan sağlığına da önemli oranda zarar verirler.

\subsection{Zehirli Boyalar}

Deniz araçlarının su içinde kalan yüzeylerine kabuklu, alg ve mikroorganizma gibi canlıların yapışmasıyla oluşan tabakaya fouling denir. Foulingin pek çok olumsuz etkisi nedeniyle deniz araçlarının karine kısmı anti-fouling boya ile boyanırlar. Geçmişte kullanılan ancak günümüzde yasaklanan tribütilkalay (TBT) ihtiva eden boyaların deniz çevresine önemli zararlar verdiği belirlenmiştir. TBT’nin toksik etkileri deniz ekolojisi bakımından son derece önemlidir. Deniz suyunda TBT düşük konsantrasyonda bulunsa dahi alglerin, omurgasızların, kabukluların ve balıkların üreme ve gelişimini olumsuz olarak etkilemektedir. TBT yasaklandıktan sonra kullanılmaya başlanan bakır ihtiva eden boyalar da deniz canlılarına toksik etki etmektedir (Okay, 2014; Amara ve ark., 2018). Türkiye'de yapılan bir çalışmada, tribütilkalay miktarlarının İskenderun, Mersin, Marmaris ve Antalya limanlarında sırasıyla 83, 936, 353 ve 184 ng/L olduğu belirlenmiştir. Yine aynı limanlarda ölçülen dibütil kalay değerlerinin ise sırasıyla 486, 366, 742 ve 677 ng/L olduğu saptanmıştır (Duydu, 1993). İngiltere'nin güney batı sahillerinde 1984 yılında yapılan bir çalışmada liman dişı deniz sularında tribütilkalay düzeyi $<0.10 \mu \mathrm{g} / \mathrm{L}$ olarak belirlenirken, bu değerin liman içi sularda çok daha yüksek olduğu ve Plymouth Sutton limanında $0.88 \mu \mathrm{g} / \mathrm{L}$ düzeyine ulaştığ bildirilmiştir. Aynı çalışmada deniz sularında tribütil kalay düzeyinin zaman zaman toksikolojik eşik düzeyini aştığ1 vurgulanmıştır (Cleary ve Stebbing, 1985).

\subsection{Liman Dip Taraması}

Deniz ve kıyı sularında yapılan dip taraması faaliyetleri deniz ekolojisini olumsuz etkilemektedir. Ayrıca dip taraması sonucu ortaya çıkan malzemenin çevre ve insan sağlığına zarar vermeden deniz ortamına boşaltılması veya bertaraf edilmesi oldukça önemlidir. Türkiye'de yılda yaklaşık 3 milyon $\mathrm{m}^{3}$ deniz dip tarama malzemesi çıkarılmakta olup bunun önemli bir kısmı gemilerle açık denize boşaltılmakta, çok az bir kısmı ise bertaraf edilmektedir. Liman ve çevresinde bulunan deniz alanlarındaki dip sedimentleri limanlardaki faaliyetler sonucu kirlenmektedir. Kontaminasyon daha çok organik ve inorganik kirleticilerden kaynaklanmaktadır. Deniz dibi tarama materyalinde poliaromatik hidrokarbonlar $(\mathrm{PAH})$ poliklorobifeniller (PCB, pestisitler ve tribütilkalay gibi yüksek toksisiteli organik bileşikler, ağır metaller, nitrat ve fosfat gibi maddeler bulunmaktadır (Başar ve ark., 2017). Liman taramalarında deniz suyunda bulanıklık oluşması, tarama sahasındaki yaşam alanlarının tahribi ve bentik canlıların telef olması, siltasyon hızının değişimi, liman içi sularda 
oksijen azalması, tarama sonucu dipten alınan malzemenin denizin başka alanlarına dökülerek kontamine olmuş materyalin kirliliğe neden olması, karşılaşılan ekolojik problemlerdendir (OECD, 2011).

\subsection{Liman Ardbölge Trafiği}

Limanların ardbölgelerinden malların limana taşınması ve limana gelen malların ardbölgelere ulaştırılmasında ulaşım zincirinin verimliliği, mod seçimi ve yakıtların standardı ile kullanılan araçlar çevre kirliliği bakımından son derece önemlidir. Genel olarak demir yolu ile ulaşım, karadaki su yollarının kullanılması ve kısa deniz taşımacılığı gibi ton başına daha az enerji gerektiren sistemler daha az çevre kirliliğine neden olur (OECD, 2011). Dolayısıyla liman ardbölgelerine ulaşımın sağlanmasında taşınan bir ton yük başına daha fazla enerji harcanan karayolu taşımacılığı, alternatiflerin olması durumunda pek tercih edilmemektedir. Ardbölge ile liman arasında yapılan taşımacılıkta ton başına en az emisyona neden olan taşımacılık modunun seçilmesi çevre problemlerinin en aza indirilmesi bakımından son derece önemlidir. Ayrıca toprak kirliliği, su kaynaklarının kirlenmesi, tehlikeli atıkların oluşması gibi diğer çevresel etkiler de ulaşım yatırımlarının inşaat dönemlerindeki önemli çevresel unsurlar olarak ortaya çıkmaktadır.

\section{Sonuçlar ve Öneriler}

Liman aktivitelerinin çevresel etkileri hem limanın inşaatı aşamasında ve hem de liman operasyonları sonucu ortaya çıkmaktadır. Bu etkiler daha çok liman ve çevresinde oluşmakta ve su, hava ve gürültü kirliliğine neden olarak, gerek deniz canlılarını ve gerekse de liman ve çevresinde yaşayan insanları olumsuz olarak etkilemektedir. Deniz ve kıyı ekosistemleri birçok bitkisel ve hayvansal canlı için yaşam alanı oluşturmaktadır. Liman inşaatları için yapılan deniz dolguları ve sonraki aşamalarda uygulanan dip taramaları deniz dibinde habitat kayıplarına neden olmaktadır. Özellikle petrol ve petrol türevi maddelerin sulara bulaşması liman içi ve çevresindeki alanlarda başta balıklar olmak üzere birçok deniz canlısını olumsuz olarak etkilemektedir. $\mathrm{Bu}$ maddelerin biyo parçalanması sonucu oluşan toksik aromatik ürünler ve parçalanma esnasında oksijen sarfiyatının meydana gelmesi deniz ve k1yı ekosistemlerini etkilemektedir.

Liman operasyonlarının çevresel etkilerini azaltmak amacıyla çevre yönetim sistemlerini daha sistematik hale getirmek, liman atık alım tesislerinin yeterli kapasitede ve işlevsel olmasını sağlamak, limanlara gelen gemilerin, Uluslararası Denizcilik Örgütü’nün (IMO) deniz çevresini korumak amaciyla ortaya koyduğu kurallar çerçevesinde denetimlerinin liman otoriteleri tarafindan yapılmasını sağlamak gerekmektedir. Gemi ve liman içerisinde kullanılan araçlardan kaynaklanan 
gürültü ve hava kirliliğinin azaltılması için gerekli tedbirlerin alınmasını sağlamak ve bunları denetlemek, katı atıkların gemilerden usulüne uygun ayrıştırılmış olarak alınmasını sağlamak liman ve çevresinde kirliliğin azaltılması için yapılması gerekenlerdendir. Yine limanlarda gemilerden kaynaklanan emisyonu azaltmak için makine dairesi ve köprüüstü simülatörleri kullanarak limanlar için uygun gemi manevra sistemlerinin belirlenmesi sağlanmalıdır.

\section{Kaynaklar}

Amara, I., Miled, W., Slama, R.B. ve Ladhari, N., (2018). Antifouling processes and toxicity e ects of antifouling paints on marine environment. A review. Environmental Toxicology and Farmacology. 57, 115-130.

Andersson, K., Baldi, F., Brynolf, S., Lindgren, J.F. ve Granhag, L., (2016). Berlin, Springer-Verlag.

Badino A, Borelli D, Gaggero T, Rizzuto E, Schenone C., (2012). Noise emitted from ships: impact inside and outside the vessels. Procedia - Soc. Behav. Sci., 48, 868-879.

Başar, H.M., Güzel, B., Özer Erdoğan, P. ve Tolun, L., (2107). Türkiye'deki deniz dibi tarama malzemelerinin faydalı kullanım öncesi çevresel etkilerinin belirlenmesi: Ticari limanlar \& balıkçı barınakları. Journal of the Faculty of Engineering and Architecture of Gazi University 32(4), 1063-1076.

Carlton, J.T. ve College, W., (2010). The impact of maritime commerce on marine biodiversity. Brown Journal of World Affairs, 16(2), 131-142.

Cleary, J.J. ve Stebbing, A.R.D., (1985). Organotin and total tin in coastal waters of Southwest England. Marine Pollution Bulletin, 16 (9), 350-355.

ÇŞB, (2017). Çevre ve Şehircilik Bakanlığının ÇED alanında kapasitenin güçlendirilmesi için teknik yardım projesi, Su yollar1-limanlar-tersaneler, Sözleşme No 2007TR16IPO001.3.06/SER/42.

Deniz, C., Kılıç, A. ve Cıvkaroğlu, G., (2010). Estimation of shipping emissions in Candarlı Gulf, Turkey. Environ. Monit. Assess. 171, 219-228.

Duydu, Y., (1993). Organokalay bileşiklerinin yarattıkları önemli çevre sorunları, Ankara Ecz. Fak. Der., 22(12), 52-63.

Gençtürk, P., (2012). Doğu Karadeniz'deki bazı limanlarda (Trabzon, Rize, Hopa, Giresun, Ordu, Ünye) atık alım tesislerinin incelenmesi ve verimliliğinin belirlenmesi. Yüksek Lisans Tezi, Karadeniz Teknik Üniversitesi, Fen Bilimleri Enstitüsü, Trabzon.

Köseoğlu, B., Töz, A.C. ve Şakar, C., (2016). Deniz atıklarının değerlendirilmesi ve geri dönüşümü: İSTAÇ örneği. Dokuz Eylül Üniversitesi Denizcilik Fakültesi Dergisi, ULK 2015 özel sayı, 153-177.

OECD (2011), Environmental impacts of international shipping: The role of ports, OECD Publishing. Retrieved from: http://dx.doi.org/10.1787/9789264097339-en.

Okay, O.S., (2014). Antifouling içeren gemi boyalarının uluslararası kurallar çerçevesinde kirletici etkilerinin incelenmesi, Gemi Mühendisliği ve Sanayimiz Sempozyumu, 24-25 Aralık 2004.

Schenone, C., Pittaluga, I., Repetto, S. ve Borelli, D., Noise pollution management in ports: a brief review and the EU MESP Project experience, Proceedings of the 21st International Congress on Sound and Vibration, Beijing, China, 2014.

Uçar, (2014), Samsun ili limanlarına gelen gemilerin oluşturduğu egzoz gazı emisyonlarının incelenmesi ve çevresel etkileri, Denizcilik Uzmanlık Tezi, Samsun. 